\title{
Association of Cystatin C and Depression in Healthy Elders: The Health, Aging and Body Composition Study
}

\author{
Evgueni Minev $^{\mathrm{a}}$ Mark Unruh $^{\mathrm{a}}$ Michael G. Shlipak $^{\mathrm{e}}$ Eleanor Simsonick $^{\mathrm{g}}$ \\ Kristine Yaffe ${ }^{f}$ Tennille S. Leak ${ }^{c}$ Anne B. Newman ${ }^{b, c}$ Linda F. Fried ${ }^{a, c, d}$ \\ for the Health ABC Study

\begin{abstract}
${ }^{a}$ Renal-Electrolyte Division and bivision of Geriatric Medicine, University of Pittsburgh School of Medicine, 'Department of Epidemiology, University of Pittsburgh Graduate School of Public Health, and d Renal Section, VA Pittsburgh Healthcare System and Renal-Electrolyte Division, Pittsburgh, Pa., e'General Internal Medicine Section, Veterans Affairs Medical Center, and Departments of Medicine, Epidemiology and Biostatistics, University of California, ${ }^{\mathrm{f}}$ Departments of Psychiatry, Neurology and Epidemiology and Biostatistics, University of California, and Veterans Affairs Medical Center, San Francisco, Calif., and 9 National Institute of Aging, National Institute of Health,
\end{abstract} \\ Baltimore, Md., USA
}

\section{Key Words}

Depression, elderly $\cdot$ Cystatin C $\cdot$ Chronic kidney disease

\begin{abstract}
Background/Aims: Depression is highly prevalent in individuals with advanced kidney disease, but is less well studied in individuals with milder disease. We evaluated the association between kidney function and depression in the Health, Aging and Body Composition (Health $A B C$ ) study. Methods: The study enrolled 3,075 community-dwelling black and white adults aged 70-79 years. Kidney function was measured by cystatin $C$ and estimated glomerular filtration rate (eGFR). The main outcome was incident treated depression. Results: $52 \%$ of participants had low ( $\leq 1.0), 33 \%$ intermediate $(>1-1.25)$ and $15 \%$ high cystatin $C(>1.25)$. Kidney function and depression were not associated at baseline. Of 2,731 nondepressed participants at baseline, 95 developed incident depression during follow-up. In unadjusted Cox proportional hazard models, hazard ratios (HR) for incident depression were 1.89 (95\% confidence interval (CI) 1.21-2.97)
\end{abstract}

for the intermediate and 2.17 ( $\mathrm{Cl} 1.24-3.79)$ for the high cystatin $\mathrm{C}$ group. Intermediate $(\mathrm{HR}=1.84)$ and high $(\mathrm{HR}=2.1)$ serum cystatin $C$ remained associated with incident depression in adjusted models. Chronic kidney disease, defined by an eGFR $<60 \mathrm{ml} / \mathrm{min} / 1.73 \mathrm{~m}^{2}$, was not associated with depression. Conclusion: Participants with higher cystatin $C$ had an increased likelihood of developing treated depression. Future studies should target this high-risk group.

Copyright $\odot 2010$ S. Karger AG, Basel

\section{Introduction}

Major depression is more prevalent in individuals with chronic medical conditions [1] and nearly doubles their total healthcare costs [2]. The prevalence of depression in hemodialysis patients approaches $30 \%$ in some dialysis units [3], with almost half of patients displaying depressive symptoms upon initiation of dialysis [4]. In dialysis patients, depression is associated with poorer quality of life, inferior nutritional status, nonadherence to treat-

\section{KARGER}

Fax +41613061234 E-Mail karger@karger.ch www.karger.com
(C) 2010 S. Karger AG, Base $1660-2110 / 10 / 1163-0241 \$ 26.00 / 0$

Accessible online at: www.karger.com/nec
Evgueni Minev

Renal-Electrolyte Division, University of Pittsburgh School of Medicine

3550 Terrace Street

Pittsburgh, PA 15216 (USA)

Tel. +1 412647 3118, Fax +1 412647 6222, E-Mail evgueni.minev@ gmail.com 
ment and is linked to increased hospitalization rate and mortality [5-8]. In kidney transplant recipients, who generally have a better quality of life than dialysis patients, depressive symptoms are similarly high, with up to $22 \%$ suffering from moderate to severe depression after transplantation [9]. According to the United States Renal Data System, the cumulative incidence of depression (based on ICD-9 codes) was found to be 5.1, 7.3 and 9.1\% one, two and three years after transplantation, respectively [10].

Many complications of end-stage renal disease are present in individuals with milder degrees of kidney dysfunction, but the risk of depression has been less well studied. Hedyati et al. [11] found that depression was highly prevalent in advanced chronic kidney disease (CKD ; stage 4/5). In contrast, Odden et al. [12] found that mild kidney dysfunction was not associated with depressive symptoms in individuals with coronary artery disease. Whether kidney disease is associated with incident depression has also not been studied.

We assessed the association between kidney function and the prevalence and incidence of depression in the Health, Aging and Body Composition (Health ABC) study, a longitudinal study of initially well-functioning older individuals.

\section{Methods}

\section{Subjects}

Health $\mathrm{ABC}$ is a prospective study that enrolled 3,075 community-dwelling older adults aged 70-79 years living in Memphis, Tenn., USA, or Pittsburgh, Pa., USA, between 1997 and 1998. All of the black and a random sample of the white Medicare-eligible adults within designated zip code areas were contacted in order to generate a balanced cohort. Inclusion criteria for participation were: (1) no reported difficulty performing activities of daily living, walking a quarter of a mile or climbing 10 steps without resting or needing assistive devices; (2) absence of life-threatening illness, and (3) no plans to leave the area for 3 years. The study was IRB approved at the study sites and coordinating center. All participants gave informed consent. Individuals were evaluated yearly at clinic visits or by telephone interviews.

\section{Depression Diagnosis}

Prevalent depression was defined as actively treated depression by use of medications or self-report of current or past depression at year 1. Medication data was collected and available for years 1, 2, 3, 5 and 6. Presence of depressive symptoms was defined using the short version of the Center for Epidemiologic Depression Scale (CES-D10). A score $\geq 10$ was defined as the presence of depressive symptoms. CES-D was administered at years $1,3,4,5$, 6 and 8.

For this analysis, the main outcome variable was incident treated depression among persons without prior depression history. New diagnoses of depression were detected at annual clinic visits by self-report or use of antidepressant drugs. The use of antidepressant drugs was considered present only when the reason for use was coded as depression or mood disorder. This was chosen as the primary outcome, as there is an overlap between symptoms of uremia and physical symptoms of depression. Secondary analyses defined incident depression as (1) self-report and current use of antidepressant medications or CES-D10 $\geq 10$ and (2) use of any antidepressant medication (without report of depression).

\section{Kidney Function}

Kidney function was defined using cystatin $\mathrm{C}$ and creatininebased estimated glomerular filtration rate (eGFR). Based on prior reports defining cystatin $\mathrm{C}$ and mortality and dementia [13], participants were divided into 3 groups: (1) cystatin $C \leq 1.0$, (2) $1.0<$ cystatin $\mathrm{C} \leq 1.25$ and (3) cystatin $\mathrm{C}>1.25$. We also analyzed eGFR using serum creatinine and calculated using the 4-variable Modification of Diet in Renal Disease (MDRD) formula [14]. CKD was defined as an eGFR $<60 \mathrm{ml} / \mathrm{min} / 1.73 \mathrm{~m}^{2}$ [14].

Samples were drawn after an 8 -hour fast and stored at $-70^{\circ} \mathrm{C}$ until they were assayed at the study core laboratory (University of Vermont). Cystatin C was measured using a BNII nephelometer (Dade Behring Inc., Deerfield, Ill., USA) that utilized a particleenhanced immunonephelometric assay (N Latex Cystatin C) [15]. Creatinine was measured using the colorimetric technique on a Johnson \& Johnson VITROS 950 Chemistry Analyzer (Johnson \& Johnson, New Brunswick, N.J., USA) using the enzymatic method.

\section{Covariates}

Covariates were selected a priori as those that might confound the relationship between depression and kidney disease, and included: demographics (age, sex and self-reported race), level of education, whether the participant lived alone, whether a spouse or relative had died within the past year, diabetes mellitus (selfreport or use of a diabetes drug at year 1), and inflammatory markers [C-reactive protein (CRP), interleukin-6 (IL-6), tumor necrosis- $\alpha$ (TNF- $\alpha)]$. Measures of IL- 6 and TNF- $\alpha$ were performed using ELISA kits from R\&D Systems (Minneapolis, Minn., USA). CRP was measured using ELISA (Calbiochem, San Diego, Calif., USA). Detectable limits were $0.10 \mathrm{pg} / \mathrm{ml}$ for IL-6, $0.18 \mathrm{pg} / \mathrm{ml}$ for TNF- $\alpha$ and $0.007 \mathrm{mg} / \mathrm{l}$ for CRP. Inflammatory markers were log transformed because of skewness.

\section{Statistical Analysis}

Baseline characteristics were compared across cystatin C groups and tested for significant differences using the one-way ANOVA test for trend (for continuous variables) or the $\chi^{2}$ with Armitage test for trend (for categorical variables). Similar analyses were performed for the incident depression status. Prevalent depression was analyzed using logistic regression. Incident depression was analyzed using Cox-proportional hazard models to assess the unadjusted and adjusted hazard ratios (HR) for each cystatin $\mathrm{C}$ group (reference cystatin $\mathrm{C} \leq 1$ ). Since incident depression was only assessed as discrete time points, a discrete model was also run and the results were the same. We repeated these models using MDRD-defined CKD. Proportionality was assessed statistically by testing for a time interaction. To assess whether cardiovascular disease affected the results, we ran an additional model with prevalent cardiovascular disease (stroke or coronary heart disease based on self-report, medication use or a health care 
Table 1. Baseline characteristics by cystatin $\mathrm{C}$ group

\begin{tabular}{|c|c|c|c|c|}
\hline \multirow[t]{2}{*}{ Characteristics } & \multicolumn{3}{|c|}{ Cystatin C level } & \multirow{2}{*}{$\begin{array}{l}\mathrm{p} \text { for } \\
\text { trend }\end{array}$} \\
\hline & $\begin{array}{l}0-1.00 \mathrm{mg} / \mathrm{l} \\
(\mathrm{n}=1,586)\end{array}$ & $\begin{array}{l}1.01-1.25 \mathrm{mg} / \mathrm{l} \\
(\mathrm{n}=1,012)\end{array}$ & $\begin{array}{l}>1.25 \mathrm{mg} / \mathrm{l} \\
(\mathrm{n}=446)\end{array}$ & \\
\hline Mean age, years & $73.2(2.8)$ & $74(2.9)$ & $74.33(2.92)$ & $<0.0001$ \\
\hline White, $\%$ & 53.7 & 63.9 & 62.8 & $<0.0001$ \\
\hline Male sex, \% & 41.5 & 56.5 & 55.4 & $<0.0001$ \\
\hline Diabetes mellitus, \% & 13.5 & 14.4 & 23.4 & $<0.0001$ \\
\hline Postsecondary education, \% & 41.2 & 42.6 & 43.3 & 0.68 \\
\hline Mean number of household contacts & $0.97(1.18)$ & $0.97(0.98)$ & $0.91(0.87)$ & 0.55 \\
\hline Loss of a spouse, $\%$ & 3.4 & 3.8 & 1.6 & 0.25 \\
\hline Mean creatinine, $\mathrm{mg} / \mathrm{dl}$ & $0.93(0.17)$ & $1.07(0.2)$ & $1.49(0.87)$ & $<0.0001$ \\
\hline Mean eGFR, $\mathrm{ml} / \mathrm{min} / 1.73 \mathrm{~m}^{2}$ & $80.34(14.49)$ & $69.73(12.08)$ & $53.18(14.61)$ & $<0.0001$ \\
\hline Mean log IL-6 & $0.23(0.27)$ & $0.31(0.27)$ & $0.42(0.26)$ & $<0.0001$ \\
\hline Mean log TNF- $\alpha$ & $0.43(0.16)$ & $0.54(0.15)$ & $0.67(0.17)$ & $<0.0001$ \\
\hline Mean log CRP & $0.24(0.35)$ & $0.29(0.36)$ & $0.4(0.42)$ & $<0.0001$ \\
\hline Prevalent depression, \% & 10.5 & 9.9 & 10.5 & 0.88 \\
\hline Incident depression, \% & 2.2 & 4.1 & 4.3 & 0.01 \\
\hline Prevalent depressed mood, \% & 5.1 & 6.9 & 5.2 & 0.14 \\
\hline Incident depressed mood, \% & 22.8 & 20.2 & 22.2 & 0.37 \\
\hline
\end{tabular}

Figures in parentheses indicate SD.

financing administration diagnosis code) plus incident cardiovascular disease during follow-up as a time-dependent covariate. Analyses were conducted using Number Cruncher Statistical Software 2003 (Jerry Hintz, Kaysville, Utah, USA) and SAS 9.2 (Cary, N.C., USA).

\section{Results}

Participant characteristics at baseline are summarized in table 1 . Baseline serum cystatin $\mathrm{C}$ measures were missing for 31 individuals (1\%), who were excluded from further analysis. Of the 3,044 participants, 1,586 (52\%) had low ( $\leq 1.0), 1,012(33 \%)$ had intermediate $(>1-1.25)$ and 446 (15\%) had high cystatin C levels (>1.25). The overall mean cystatin C level was $1.05 \pm 0.34 \mathrm{mg} / \mathrm{l}$. Participants with higher serum cystatin $\mathrm{C}$ levels were more likely to be white, male and diabetic and to have older age and higher creatinine, IL-6, TNF- $\alpha$ and CRP levels. Loss of a spouse, postsecondary education and the mean number of household contacts did not differ among the cystatin C groups.

There were 299 participants with prevalent depression at year 1. Prevalent depression did not differ across cystatin C groups (10.5 vs. 9.9 vs. $10.5 \%, p=0.88$ for low, intermediate and high cystatin $\mathrm{C}$, respectively). Multivariable adjustment did not affect these results [odds ratio
0.98 and $95 \%$ confidence interval (CI) $0.72-1.22$; odds ratio 1.01 and $95 \%$ CI $0.72-1.42$ for intermediate and high cystatin $\mathrm{C}$, respectively]. Depression also did not vary by CKD (9.4 vs. $12 \%, \mathrm{p}=0.21)$. Similar findings were found if prevalent depression was defined as CES-D alone or medication use alone.

Ninety-five out of 2,731 participants without prevalent depression developed incident depression during the study follow-up. These individuals were more likely to be white, female and to have a higher mean serum cystatin $\mathrm{C}$ level $(1.13 \pm 0.57$ vs. $1.04 \pm 34 \mathrm{mg} / \mathrm{l}, \mathrm{p}=0.025)$. Creatinine and eGFR were not significantly different. In the unadjusted Cox proportional hazard models, the intermediate and high cystatin $\mathrm{C}$ groups were associated with incident depression $(\mathrm{HR}=1.89$ for intermediate and $\mathrm{HR}=2.17$ for the high cystatin $\mathrm{C}$ group). CKD was not related to incident treated depression (table 2). After adjustment for age, sex, race, absence of household contacts, inflammatory biomarkers and diabetes, intermediate $(\mathrm{HR}=1.84)$ and high serum cystatin $\mathrm{C}(\mathrm{HR}=2.1)$ remained associated with incident depression. There was no interaction between cystatin $\mathrm{C}$ groups and race or gender. CKD was not associated with incident depression in adjusted analyses.

We performed a number of sensitivity analyses. In contrast to treated depression, when depression was de- 
Table 2. Association of kidney function with incident treated depression

\begin{tabular}{lllll}
\hline & HR & p value & Adjusted $^{\mathrm{a}}$ & p value \\
\hline Cystatin $\leq 1.0 \mathrm{mg} / \mathrm{l}$ & 1.0, ref. & - & 1.0, ref. & - \\
$1<$ cystatin $\leq 1.25$ & $1.89(1.21-2.97)$ & 0.006 & $1.84(1.11-3.03)$ & 0.02 \\
Cystatin $>1.25 \mathrm{mg} / 1$ & $2.17(1.24-3.79)$ & 0.007 & $2.10(1.08-4.10)$ & 0.03 \\
eGFR $\geq 60 \mathrm{ml} / \mathrm{min} / 1.73 \mathrm{~m}^{2}$ & 1.0, ref. & - & 1.0, ref. & - \\
eGFR $<60 \mathrm{ml} / \mathrm{min} / 1.73 \mathrm{~m}^{2}$ & $1.28(0.80-2.04)$ & 0.31 & $1.03(0.62-1.73)$ & 0.91 \\
\hline
\end{tabular}

Figures in parentheses are presented with a $95 \%$ confidence interval.

${ }^{a}$ Adjusted for age, gender, race, living alone status, diabetes and normalized inflammatory biomarkers.

Table 3. Association of cystatin $\mathrm{C}$ with depression, based on different definitions of incident depression

\begin{tabular}{|c|c|c|c|c|}
\hline \multirow[t]{2}{*}{ Incident depression, defined as } & \multicolumn{2}{|c|}{ Unadjusted Cox model } & \multicolumn{2}{|c|}{ Adjusted Cox model ${ }^{1}$} \\
\hline & $1<$ cystatin $\leq 1.25$ & cystatin $>1.25$ & $1<$ cystatin $\leq 1.25$ & cystatin $>1.25$ \\
\hline $\begin{array}{l}\text { Depression by medication use and } \\
\text { self-report }(n=95)\end{array}$ & $\begin{array}{l}\mathrm{HR}=1.89 \\
\mathrm{CI}=1.21-2.97 \\
\mathrm{p}=0.006\end{array}$ & $\begin{array}{l}\mathrm{HR}=2.17 \\
\mathrm{CI}=1.24-3.79 \\
\mathrm{p}=0.007\end{array}$ & $\begin{array}{l}\mathrm{HR}=1.84 \\
\mathrm{CI}=1.11-3.03 \\
\mathrm{p}=0.02\end{array}$ & $\begin{array}{l}\mathrm{HR}=2.10 \\
\mathrm{CI}=1.08-4.10 \\
\mathrm{p}=0.03\end{array}$ \\
\hline $\begin{array}{l}\text { Depressed mood, CES-D } 10 \geq 10 \\
(\mathrm{n}=664)\end{array}$ & $\begin{array}{l}\mathrm{HR}=0.91 \\
\mathrm{CI}=0.77-1.08 \\
\mathrm{p}=0.30\end{array}$ & $\begin{array}{l}\mathrm{HR}=1.11 \\
\mathrm{CI}=0.89-1.39 \\
\mathrm{p}=0.35\end{array}$ & $\begin{array}{l}\mathrm{HR}=1.01 \\
\mathrm{CI}=0.99-1.04 \\
\mathrm{p}=0.71\end{array}$ & $\begin{array}{l}\mathrm{HR}=0.97 \\
\mathrm{CI}=0.81-1.15 \\
\mathrm{p}=0.24\end{array}$ \\
\hline $\begin{array}{l}\text { Combined incident depressed mood } \\
\text { and medication }(\mathrm{n}=596)\end{array}$ & $\begin{array}{l}\mathrm{HR}=0.95 \\
\mathrm{CI}=0.78-1.14 \\
\mathrm{p}=0.57\end{array}$ & $\begin{array}{l}\mathrm{HR}=1.14 \\
\mathrm{CI}=0.89-1.47 \\
\mathrm{p}=0.29\end{array}$ & $\begin{array}{l}\mathrm{HR}=0.98 \\
\mathrm{CI}=0.79-1.21 \\
\mathrm{p}=0.83\end{array}$ & $\begin{array}{l}\mathrm{HR}=1.17 \\
\mathrm{CI}=0.88-1.56 \\
\mathrm{p}=0.29\end{array}$ \\
\hline
\end{tabular}

${ }^{1}$ Reference cystatin $\mathrm{C}<1.0$; adjusted for gender, race, living alone status, diabetes and normalized inflammatory biomarkers.

fined as a depressed mood alone or a depressed mood plus treatment with medication, cystatin $\mathrm{C}$ was not associated with incident depression (table 3 ). To assess whether differential coding for depression accounted for the results, we also evaluated the use of antidepressants for any reason. Using this definition for depression, the intermediate and high cystatin $\mathrm{C}$ levels remained associated with incident depression after adjusting for age, sex, race, living alone status, inflammatory biomarkers and diabetes. To assess whether grieving masked a difference in incident depressed mood, we excluded all individuals who reported loss of a spouse or loss of a relative in the preceding year. In this model, there was no association between cystatin $\mathrm{C}$ and an incident depressed mood, defined as a CES-D10 score $\geq 10$, as the intermediate and high cystatin C groups had HR $=0.75$ (CI 0.53-1.06) and $\mathrm{HR}=0.8$ (CI 0.49-1.3), respectively, with an overall $\mathrm{p}=0.24$. The addition of cardiovascular disease (prevalent and inci- dent) did not appreciably change the results [HR for intermediate is 1.73 (CI 1.05-2.85) and high is 2.01 (CI 1.033.91)] regarding cystatin $C$ levels.

\section{Discussion}

We found that, among community-resident elder adults, those with higher cystatin $C$ levels had an increased likelihood of developing depression that was recognized and treated with antidepressant medication during the study follow-up although there was no association with prevalent depression. The participants in the higher cystatin $\mathrm{C}$ groups were twice as likely to be diagnosed with depression as the participants in the low cystatin $\mathrm{C}$ group. Cystatin $\mathrm{C}$ categories were not associated with the development of a depressed mood during follow-up as defined by a CES $\geq 10$. CKD, defined as a creatinine- 
based eGFR $<60 \mathrm{ml} / \mathrm{min} / 1.73 \mathrm{~m}^{2}$, was not associated with incident depression by either definition.

The lack of association of kidney function with depressive symptoms is consistent with Odden et al. [12], who evaluated individuals with coronary artery disease in a cross-sectional analysis. They found that the prevalence of depressive symptoms did not differ between individuals with and without kidney disease (17 vs. 19\%, $\mathrm{p}=0.4)$.

We found a discrepancy between incident depression defined by treatment and incident depressive symptoms. Self-reported depressive symptoms in later life are common, and their presence carries a more than 5-fold higher risk for developing major depression at year 1 [16]. Approximately one quarter of the individuals in our study had CES-D10 scores over 10 during the follow-up, but less than $2 \%$ of participants were diagnosed and treated for depression. Kidney function was not associated with incident depressive symptoms. One possible explanation is that individuals with higher cystatin $\mathrm{C}$ are sicker and had more contacts with medical personnel, which increased the likelihood that depression would be detected and treated. Individuals who had a depressed mood by positive CES-D10 scores but lower cystatin C levels may not have sought medical attention and therefore would not have been treated for depression, even if they had the disease. It is also possible that individuals with an elevated cystatin $\mathrm{C}$ had a severer depression that was recognized and treated.

A discrepancy between cystatin C and creatininebased measures of kidney function with outcomes has been found previously, especially in older individuals [17, 18]. Cystatin $C$ has been shown to linearly associate with mortality and cardiovascular disease. In contrast, serum creatinine often shows a threshold effect or a U-shaped relationship [19]. Serum creatinine is generated in muscle, and levels of creatinine vary with both kidney function and muscle mass. In older individuals, especially individuals with weight loss due to illness or other processes, creatinine can be a poor marker of kidney function. The MDRD formula adjusts for age in order to account for age-related decline in muscle mass. However, the change is an average and does not account for the variability in loss of lean mass with disease. Cystatin C is less affected by muscle mass and may be a better marker of kidney function in older individuals. This could account for the discrepancy. Alternatively, cystatin $\mathrm{C}$ may be directly associated with depression in the elderly through direct effects on the brain. Cystatin C colocalizes with $\beta$ amyloid in the brains of patients with Alzheimer's disease
[20]. Late-life depression is a risk factor for the development of Alzheimer's disease [21] and, in a prior analysis, we found that cystatin $\mathrm{C}$ was associated with cognitive decline [13]. We cannot rule out that the stronger relationship of cystatin $\mathrm{C}$ with depression relates to nonkidney determinants. The results persist after controlling for inflammation, diabetes and cardiovascular disease, but there may be other determinants of cystatin $C$ that explain the results.

The main strengths of our study include the large sample size, community-dwelling well-functioning individuals and long longitudinal follow-up with regular assessments of depression. The study also had limitations. As a community-based study, most patients have moderate kidney disease (stage $3 \mathrm{CKD}$ ) and fewer individuals have advanced kidney disease. Only 95 participants developed new depression during the study follow-up, limiting power. Depression was not diagnosed by the 'gold standard' psychiatric interview. Kidney function was only assessed once; while this is common in epidemiologic studies, CKD is defined based on a persistent decline in kidney function. It is possible that individuals were misclassified as having kidney dysfunction. We also could not assess whether depression was more common in individuals whose kidney disease worsened over the course of the study.

Our findings have important clinical implications. The prevalence of kidney dysfunction in the elderly is rising, and requires complex medical care, diet, and lifestyle modifications. Depression, on the other hand, can lead to nonadherence to treatment, increased healthcare costs and worse quality of life. Thus, it is clinically important for healthcare providers to screen for, diagnose and treat depression in this population.

References
Egede L: Major depression in individuals with chronic medical disorders: prevalence, correlates and association with health resource utilization, lost productivity and functional disability. Gen Hosp Psychiatry 2007;29:409-416

2 Unützer J, Schoenbaum M, Katon W, Fan MY, Pincus H, Hogan D, Taylor J: Healthcare costs associated with depression in medically ill fee-for-service Medicare participants. J Am Geriatr Soc 2009;57:506-510.

- 3 Hedayati S, Bosworth H, Kuchibhatla M, Kimmel P, Szczech L: The predictive value of self-report scales compared with physician diagnosis of depression in hemodialysis patients. Kidney Int 2006;69:1662-1668

(1) 
4 Watnick S, Kirwin P, Mahnensmith R, Concato J: The prevalence and treatment of depression among patients starting dialysis. Am J Kidney Dis 2003;41:105-110.

$\checkmark 5$ Koo JR, Yoon JW, Kim SG, et al: Association of depression with malnutrition in chronic hemodialysis patients. Am J Kidney Dis 2003;41:1037-1042.

6 Ibrahim S, El Salamony O: Depression, quality of life and malnutrition-inflammation scores in hemodialysis patients. Am J Nephrol 2008;7:784-791.

$>7$ Hedayati S, Bosworth H, Briley L, Sloane R, Pieper C, Kimmel P, Szczech L: Death or hospitalization of patients on chronic hemodialysis is associated with a physician-based diagnosis of depression. Kidney Int 2008;74: 930-936.

-8 Cukor D, Rosenthal D, Jindal R, Brown C, Kimmel P: Depression is an important contributor to low medication adherence in hemodialyzed patients and transplant recipients. Kidney Int 2009;75:1223-1229.

-9 Akman B, Ozdemir F, Sezer S, Micozkadioglu H, Haberal M: Depression levels before and after transplantation. Transplant Proc 2004;36:111-113.

-10 Dobbels F, Skeans M, Snyder J, Tuomari A, Maclean J, Kasiske B: Depressive disorder in renal transplantation: an analysis of Medicare claims. Am J Kidney Dis 2008;51:819828.
11 Hedyati S, Jiang W, O'Connor C, Kuchibhatla M, Krishnan K, Cuffe M, Blazing M, Szczech L: The association between depression and chronic kidney disease and mortality among patients hospitalized with congestive heart failure. Am J Kidney Dis 2004;44: 207-215.

12 Odden M, Whooley M, Shlipak M: Depression, stress, and quality of life in persons with chronic kidney disease: the Heart and Soul Study. Nephron Clin Pract 2006;103:c1c7.

13 Yaffe K, Lindquist K, Shlipak M, Simonsick E, Fried L, Rosano C, Satterfield S, Atkinson H, Windham B, Kurella-Tamura M: Cystatin $\mathrm{C}$ as a marker of cognitive function in elders: findings from the health $\mathrm{ABC}$ study. Ann Neurol 2008;63:798-802.

14 National Kidney Foundation: K/DOQI clinical practice guidelines for chronic kidney disease: evaluation, classification, and stratification - evaluation of laboratory measurements for clinical assessment of kidney disease. Am J Kidney Dis 2002;40(suppl 1):S76-S111.

15 Erlandsen E, Randers E, Kristensen J: Evaluation of the Dade Behring N Latex Cystatin C assay on the Dade Behring Nephelometer II System. Scand J Clin Lab Invest 1999;59: $1-8$.
16 Lyness JM, Heo M, Datto CJ, Ten Have TR, Katz IR, Drayer R, Reynolds CF 3rd, Alexopoulos GS, Bruce ML: Outcomes of minor and subsyndromal depression among elderly patients in primary care settings. Ann Intern Med 2006;144:496-504

17 Shlipak M, Sarnak M, Katz R, Fried L, Seliger S, Newman A, Siscovick D, Stehman-Breen $\mathrm{C}$ : Cystatin $\mathrm{C}$ and the risk of death and cardiovascular events among elderly persons. $\mathrm{N}$ Engl J Med 2005;352:2049-2060.

-18 Shlipak MG, Katz R, Sarnak MJ, Fried LF, Newman AB, Stehman-Breen C, Seliger SL, Kestenbaum B, Psaty B, Tracy RP, Siscovick DS: Cystatin C and prognosis for cardiovascular and kidney outcomes in elderly persons without chronic kidney disease. Ann Intern Med 2006;145:237-246.

19 Fried L, Katz R, Sarnak M, Shlipak M, Chaves P, Jenny N, Stehman-Breen C, Gillen D, Bleyer A, Hirsch C, Siscovick D, Newman A: Kidney function as a predictor of noncardiovascular mortality. J Am Soc Nephrol 2005;16: 3728-3735.

20 Sastre M, Calero M, Pawlik M, Mathews PM, Kumar A, Danilov V, Schmidt SD, Nixon RA, Frangione B, Levy E: Binding of cystatin $\mathrm{C}$ to Alzheimer's amyloid beta inhibits in vitro amyloid fibril formation. Neurobiol Aging 2004;25:1033-1043.

-21 Korczyn A, Halperin I: Depression and dementia. J Neurol Sci 2009;283:139-142. 